\title{
Gastrostomy tube dislodgment acute pancreatitis
}

\author{
Eran Brauner ${ }^{*}$ and Yoram Kluger
}

\begin{abstract}
Percutaneous gastrostomy is well established root for long term feeding of patients who cannot be fed orally. The risks of percutanous gastrostomy insertion are low. Tube related complications often resolved by placing a Foley catheter or other balloon gastrostomy tube as a temporary solution. Gastrostomy tube related gastric, duodenal and billiary obstruction were reported. Gastrostomy tube related pancreatitis is scarcely described. We described a patient who suffered a pancreatitis related to Foley catheter gastrostomy dislodgment. Reviewing all reported cases of gastrostomy related pancreatitis revealed higher incidence in patient with Foley catheter used as gastrostomy and revealed questionable trends in conducting tube replacement. We suggest a proper manner for tube replacement and concluded that should a Foley catheter used as a temporary solution a replacement should be schedule in a timely manner to avoid life threatening complications.
\end{abstract}

Keywords: Pancreatitis, Gastrostomy, Percutaneous endoscopic gastrostomy (PEG), Foley catheter

\section{Introduction}

Percutaneous gastrostomy is the preferred root for long term feeding of patients who cannot be fed orally [1]. The use of percutaneous gastrostomy carries a low risk for complications. Listed among the potential life threatening complications of this procedure is obstructive pancreatitis resulting from migration of the tube and obstruction of the $2^{\text {nd }}$ part of the duodenum by the catheter's balloon. This complication is rare and only scarcely described in the English literature. Usually, when a tube related complications are encountered a Foley catheter is placed instead of a designated tube. Therefore physician taking care of patients feed via feeding tube should be aware of this complication.

Herein we describe a patient who presented to the emergency department with abdominal pain. Eventually he was diagnosed with pancreatitis resulting from the Foley catheter migration in to the $2^{\text {nd }}$ part of the duodenum. We review all published cases of pancreatitis related to feeding tube migration and suggest safety manner for tube replacement.

\section{Case presentation}

A ninety two year old patient, a resident of a nursing home, presented to the emergency department with acute general deterioration and coffee ground vomiting.

\footnotetext{
* Correspondence: e_brauner@rambam.health.gov.il

Department of General Surgery, Rambam Health Care Campus, Haifa, Israel
}

Her medical history consisted with Alzheimer's dementia and CVA (cerebro vascular accident) that resulted in dysphagia.

The patient had a percutaneous endoscopic gastrostomy (PEG) tube inserted two years prior to her admission. The PEG was replaced with a Foley catheter a year ago due to inadvertent dislodgment while nursing the patient.

At presentation the patient was agitated. Her blood pressure was $90 / 60 \mathrm{mmHg}$. Her oxygen saturation was $90 \%$. Physical examination revealed a tender abdomen. The gastrostomy tube drained coffee ground material. Laboratory studies showed marked leukocytosis of 23000 and Creatinine level was $1.4 \mathrm{mg} / \mathrm{dl}$. Urinalysis showed amylase level of 11,460 U/L.

Plain abdominal and chest radiograph were normal. No free air was detected.

An upper abdominal Ultrasound was preformed, demonstrating an enlarged gallbladder with no gallstones or sludge. There were no signs of cholecystitis but the common bile duct (CBD) was dilated to $16 \mathrm{~mm}$.

An abdominal CT with IV contrast revealed a peripancreatic fat stranding and an edematous pancreatic head. These finding were consistent with acute pancreatitis. The Foley catheter balloon was seen deep in the second part of the duodenum facing Vaters' papilla (Figure 1).

The gastrostomy tube was pulled back to the stomach and secured to the abdominal wall with silk stich. The patient was treated with fluid and analgesics. The next 


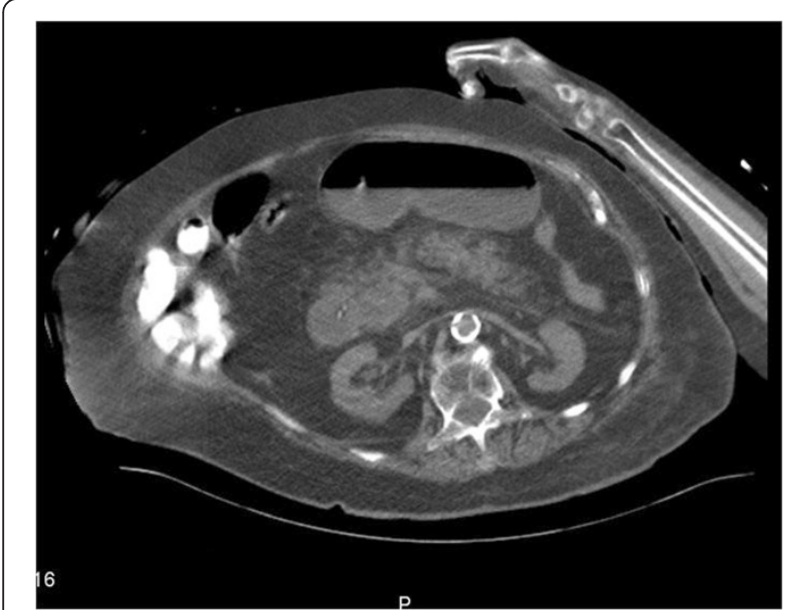

Figure 1 Abdominal CT scan showing Foley catheter balloon located in the second part of the duodenum and peripancreatic fat stranding with an edematous pancreatic head.

day a follow-up sonographic evaluation was done indicating a reduction of the CBD diameter to $11 \mathrm{~mm}$.

During her stay in the hospital her respiratory symptoms were significantly relieved, she regained hemodynamic stability, was normothermic and her abdominal tenderness disappeared. Laboratory results normalized. Bilirubin and amylase levels returned to normal within three days of her admission.

She was discharged after 6 days, having significantly improved and was sent back to her retirement home.

\section{Discussion}

Percutaneous Endoscopic Gastrostomy (PEG) tube was first described in 1980 by Gaunderer [2]. PEG is consider safe and effective method for providing long term enteral nutrition while offering advantages over nasogastric tube feeding $[3,4]$.

The incidence of short and long term complications related to PEG actual insertion is low [5]. However, tube related complications such as granulation tissue, broken or leaking tube, leakage around the tube site and stomal site infection exceed 60\% [6]. Migration of feeding gastrostomy has been described in the past as the cause for gastric outlet obstruction [7], duodenal obstruction [8] and biliary obstruction [9].

Our case presents pancreatitis as a potential complication of a balloon gastrostomy tube. In our case it seems that the Foley catheter's balloon obstructed the ampulla of Vater, therefore resulting in acute pancreatitis.

Gastrostomy tube dislodgement pancreatitis is rare. Review of the English literature revealed 10 cases of pancreatitis as a result of migration of feeding gastrostomy [5,10-17]. The first case was published in 1986 by Bui et al. [10]. He described a migration of a Foley catheter that was inadvertently left in place after establishing a permanent surgical Gastrostomy.

Selected characteristics of all eleven cases, (including our patient) are outline in Table 1. Reasons for gastrostomy tube placement varied with age, from mental retardation and cerebral palsy in the younger age to CVA in older patients. Time from the replacement of the tube to initiation of symptoms varied widely from one day to one year. None of the published cases described this complication with a new inserted PEG. In all cases, balloon feeding tube was used as a temporary solution in a well and established tract.

One case [12] describes the insertion setup to be in a medical facility and its position was confirmed using

Table 1 Characteristics of cases of feeding tube dislodgment pancreatitis

\begin{tabular}{|c|c|c|c|c|c|c|c|}
\hline Ref no. & Age (y) & Gender & Type of catheter & Diagnosis & $\begin{array}{c}\text { Time from replacement } \\
\text { to presentation }\end{array}$ & $\begin{array}{l}\text { Replacement } \\
\text { set-up }\end{array}$ & $\begin{array}{c}\text { Repositioning } \\
\text { confirmation test }\end{array}$ \\
\hline 10 & 37 & $\mathrm{~m}$ & Foley & Barium study & 1 day & NM & None \\
\hline 11 & 11 & $\mathrm{~m}$ & Foley & Barium study & 1 day & Home & None \\
\hline 12 & 32 & $f$ & Foley & Incidentally by ERCP & 6 month & Medical facility & EGD \\
\hline 13 & 26 & $f$ & $\begin{array}{c}\text { Balloon gastrostomy w/ } \\
\text { external disk bumper }\end{array}$ & $\mathrm{CT}$ & 3 month & NM & NM \\
\hline 14 & 44 & $\mathrm{~m}$ & Foley & ECRP & NM & NM & NM \\
\hline 15 & 57 & $f$ & $\begin{array}{c}\text { Balloon gastrostomy w/ } \\
\text { external disk bumper }\end{array}$ & MRCP & 4 weeks & NM & NM \\
\hline 16 & 86 & $f$ & $\begin{array}{c}\text { Balloon gastrostomy w/ } \\
\text { external disk bumper }\end{array}$ & $\mathrm{CT}$ & 4 weeks & Home & None \\
\hline 17 & 25 & $f$ & PEG w/ external disk bumper & $\mathrm{CT}$ & 3 days & Home & None \\
\hline 5 & 79 & $\mathrm{~m}$ & Foley & $\mathrm{CT}$ & Few days & Home & None \\
\hline 5 & 38 & $f$ & PEG w/ external disk bumper & $\mathrm{CT}$ & NM & NM & NM \\
\hline- & 92 & $f$ & Foley & $\mathrm{CT}$ & 1 year & Home & None \\
\hline
\end{tabular}

NM- not mentioned, ERCP- endoscopic retrograde cholangiopancreaticography, EGD- esophago gastroduadenoscopy, CT- computed tomography, MRCP- magnetic resonance cholangiopancreaticograohy, PEG- percutaneous endoscopic gastrostomy. 
upper endoscopy. In all remaining cases the insertion setup was not mentioned ( 5 cases) or was at the patient's bedside ( 5 cases). In most instances (54.5\%) no active test was done to confirm the new feeding tube position.

Tube related complication is often managed by replacing the PEG with a Foley catheter as a bridging solution, in the acute setting at the emergency room or the patient's bed side in nursing homes. In six of the reported cases (54.5\%) Foley catheter was used and five (45.5\%) reported the use of a balloon gastrostomy tube with external bolster.

One of the major disadvantages of the Foley catheter at this non formal but common use is the lack of a stopper mechanism which prevents the catheter from propelling distally with peristalsis.

Our case strengths the assumption made before [5] that the use of Foley catheter as a gastrostomy tube increases the risk of pancreatitis and should be avoided. Nevertheless in case of a Foley catheter is used as a bridging solution for a mechanically failed formal gastrostomy tube, early definitive proper elective replacement of the Foley catheter should be practiced in order to avoid potentially life threatening conditions. We strongly recommend replacing the failed or broken original feeding tube in a medical facility in order to confirm its position radiographically before using the tube. Marking the catheter at its skin level can help tracking its position periodically. We suggest that whenever a patient with feeding gastrostomy is diagnosed with pancreatitis or obstructive jaundice its position should be identified using contrast material injected through the tube. And should the diagnosis of tube dislodgment pancreatitis is made, deflating the catheter balloon and withdrawing the tube can reverse all pathologic laboratory findings and may result in the patient's prompt recovery.

\section{Consent}

Written informed consent was obtained from the patient's daughter for publication of this Case report and any accompanying images. A copy of the written consent is available for review by the Editor-in-Chief of this journal.

\section{Competing interests}

All authors declare that they have no competing interests.

\section{Authors' contributions}

EB conceived of the study, performed the literature search and carried out the drafting of the manuscript. YK participated in coordination and helped to draft the manuscript. All authors read and approved the final manuscript.

Received: 31 January 2014 Accepted: 18 March 2014

Published: 28 March 2014

\section{References}

1. Grant MD, Rudberg MA, Brody JA: Gastrostomy placement and mortality among hospitalized medicare beneficiaries. JAMA 1998, 279:1973-1976.

2. Gauderer MW, Ponsky JL, Izant RJ Jr: Gastrostomy without laparotomy: a percutaneous endoscopic technique. J Pediatr Surg 1980, 15:872-875.
3. Wicks C, Gimson A, Vlavianos P, Wicks C, Gimson A, Vlavianos P, Lombard M, Panos M, Macmathuna P, Tudor M, Andrews K, Westaby D: Assessment of the percutaneous endoscopic gastrostomy feeding tube as part of an integrated approach to enteral feeding. Gut 1992, 33:613-616.

4. Park RH, Allison MC, Lang J, Spence E, Morris AJ, Danesh BJ, Russell RI, Mills PR: Randomized comparison of percutaneous endoscopic gastrostomy and nasogastric tube feeding in patients with persisting neurological dysphagia. BMJ 1992, 304:1406-1409.

5. Shah AM, Shah N, DePasquale JR: Replacement gastrostomy tube causing acute pancreatitis: case series with review of literature. JOP 2012, 13:54-7.

6. Crosby J, Duerksen D: A retrospective survey of tube-related complications in patients receiving long-term home enteral nutrition. Dig Dis Sci 2005, 50:1712-171.7.

7. Connar RG, Sealy WC: Gastrostomy and its complication. Ann Surg 1956, 143:245-250.

8. Haws EB, Sieber WK, Kieswelter W: Complications of tube gastrostomy in infants and children. Fifteen-year review of 240 cases. Ann Surg 1966, 164:284-290.

9. Gustavsson S, Klingen G: Obstructive jaundice- complication of Foley catheter gastrostomy. Acta Chir Scand 1978, 144:325-327.

10. Bui HD, Dang CV: Acute pancreatitis: a complication of Foley catheter gastrostomy. J Natl Med Assoc 1986, 78:779-781.

11. Panicek DM, Ewing DK, Gottlieb RH, Chew FS: Gastrostomy tube pancreatitis. Pediatr Radiol 1988, 18:416-417.

12. Barthel JS, Mangum D: Recurrent acute pancreatitis in pancreas divisum secondary to minor papilla obstruction from a gastrostomy feeding tube. Gastrointest Endosc 1991, 37:638-640.

13. Duerksen DR: Acute pancreatitis caused by a prolapsing gastrostomy tube. Gastrointest Endosc 2001, 54:792-793.

14. Miele VJ, Nigam A: Obstructive jaundice and pancreatitis secondary to percutaneous endoscopic gastrostomy tube migration. $J$ Gastroenterol Hepatol 2005, 20:1802-1803.

15. Periselneris J, England R, Hull M: Balloon gastrostomy migration leading to acute pancreatitis. Gut 2006, 55(11):1673-4.

16. Imamura $\mathrm{H}$, Konagaya $\mathrm{T}$, Hashimoto $\mathrm{T}$, Kasugai $\mathrm{K}$ : Acute pancreatitis and cholangitis: a complication caused by a migrated gastrostomy tube. World J Gastroenterol 2007, 13(39):5285-5287.

17. Bhat $M$, Bridges $E$ : Acute obstructive pancreatitis caused by a migrated balloon gastrostomy tube. CMAJ 2011, 183(11):E759.

doi:10.1186/1749-7922-9-23

Cite this article as: Brauner and Kluger: Gastrostomy tube dislodgment acute pancreatitis. World Journal of Emergency Surgery 2014 9:23.

\section{Submit your next manuscript to BioMed Central and take full advantage of:}

- Convenient online submission

- Thorough peer review

- No space constraints or color figure charges

- Immediate publication on acceptance

- Inclusion in PubMed, CAS, Scopus and Google Scholar

- Research which is freely available for redistribution 